\title{
Predictors of Inadequate Mixing in Transposition of the Great Arteries a Critical Neonatal Condition
}

\author{
Iolanda Muntean ${ }^{1}$, Daniela Toma ${ }^{2}$, Rodica Togănel ${ }^{1}$ \\ ${ }^{1}$ University of Medicine and Pharmacy, Emergency Institute of Cardiovascular Diseases and Transplantation, Tîrgu Mureș, Romania \\ ${ }^{2}$ Emergency Institute of Cardiovascular Diseases and Transplantation, Tîrgu Mureș, Romania
}

\section{ABSTRACT}

Background: Simple transposition of the great arteries (TGA) is a cyanotic critical congenital heart defect representing a neonatal cardiovascular emergency, which requires surgery early after birth. In case of inadequate mixing between systemic and pulmonary circulations, creating an unrestrictive interatrial communication is mandatory. The aim of the present study was to identify the most important echocardiographic parameters that can predict the need for balloon atrial septostomy (BSA) in TGA neonates. Material and methods: We retrospectively reviewed the echocardiographic recordings of newborns with TGA referred to our emergency room during a 6-year period. We measured the following echocardiographic parameters: atrial septal defect (ASD) size, interatrial septum (IAS) length, peak/mean interatrial pressure gradient, transverse diameter of the left atrium (LA), and transverse diameter of the right atrium (RA). Also, the ratio between ASD/IAS, the ratio between LA/RA, the ratio between mitral/tricuspid annulus, the ASD peak gradient/ASD diameter and the ASD diameter/( LA:RA ratio) were calculated. Results: There were 37 neonates with simple TGA presented to the emergency room, split into two groups: those with BAS ( $n=21)$ and those without BAS ( $n=16$ ). Besides significant differences between the two groups in ASD size, peak/mean interatrial pressure gradient, and LA:RA ratio, we found that ASD peak gradient/ASD diameter was significantly higher, but ASD diameter/(LA:RA ratio) was significantly lower in the group that required BAS compared with the group without BAS. Multivariate analysis showed that ASD diameter/(LA:RA ratio) was an independent predictor of septostomy requirement, with a cut-off value of 2.58. Conclusion: ASD diameter/(LA/RA ratio) is a useful echocardiographic parameter that can provide supplementary information regarding inadequate mixing and the need for BAS in neonates with TGA.

Keywords: neonatal emergency, echocardiographic parameters, transposition of the great arteries, inadequate mixing, balloon atrial septostomy

\section{ARTICLE HISTORY}

Received: October 10, 2017

Accepted: November 14, 2017

\section{CORRESPONDENCE}

\section{Daniela Toma}

Str. Gheorghe Marinescu nr. 50 540136 Tîrgu Mureș, Romania Tel: +40745652688

E-mail: tomadaniela94@yahoo.com 


\section{INTRODUCTION}

Simple transposition of the great arteries (TGA) is a cyanotic critical congenital heart defect (CHD), representing a neonatal cardiovascular emergency that requires surgery early after birth. It accounts for about $5-7 \%$ of all CHDs, with a preponderance of male patients. ${ }^{1}$ The causes of CHD have been widely studied, being genetic, epigenetic, and environmental. ${ }^{2-7}$ Different mutations in the Nodal signaling pathway have been reported in TGA. ${ }^{8-10}$

Simple TGA is characterized by ventriculo-arterial discordance, namely the right ventricle gives rise to the aorta, and the left ventricle to the pulmonary artery. The interventricular septum is usually intact; however, a small ventricular septal defect (VSD) can occur, but with no hemodynamic significance. Consequently, two parallel circulations result, which could be fatal in the absence of an adequate mixing between them. In TGA patients, an intravenous infusion of PGE1 is recommended after birth. At the same time, in case of inadequate mixing between the systemic and pulmonary circulations, with persistent hypoxia and metabolic acidosis, creating an unrestrictive interatrial communication until the arterial switch operation is mandatory. ${ }^{11,12}$ Balloon atrial septostomy (BAS) with echocardiographic guidance, performed at the bedside, is the method of choice to enlarge the interatrial communication in neonates with TGA. ${ }^{13,14}$

Severe cyanosis is the clinical sign of poor mixing. Thus, oxygen saturation is a useful parameter to raise the suspicion of TGA and to identify cases that need septostomy. ${ }^{15-18}$

Echocardiography is an essential diagnostic tool, which, besides establishing the diagnosis of TGA, allows accurate assessment of the sites of mixing and of interatrial communication, as well as the presence of ductus arteriosus, heart chamber sizes, the direction of the shunts etc.11,19,20

The aim of the present study was to identify the most important echocardiographic parameters that can predict the need for BAS in children with TGA.

\section{MATERIAL AND METHODS}

\section{STUDY POPULATION AND GROUPING}

This retrospective study was performed by reviewing the echocardiographic records of neonates with TGA presented at the emergency room of our Pediatric Cardiology Clinic during a 6-year period, between 2012 and 2017. The inclusion criteria were: children with simple TGA or TGA associated with a tiny VSD, aged between 0 and 28 days.
All neonates with complex TGA were excluded from the present study.

The study group consisted in 37 neonates diagnosed with simple TGA. We split the study group into two groups: group 1 - TGA patients with poor mixing, who required atrial septostomy; group 2 - patients without septostomy.

\section{ECHOCARDIOGRAPHIC IMAGE DATA}

The data were obtained by reviewing the echocardiographic images of TGA patients. In patients who required BAS, the last echocardiographic acquisition just before the atrial septostomy was reviewed. We measured the following echocardiographic parameters: atrial septal defect (ASD) size, interatrial septum (IAS) length, peak/ mean interatrial pressure gradient, transverse diameter of the left atrium (LA), transverse diameter of the right atrium (RA), diameter of the mitral annulus, diameter of the tricuspid annulus, ductus arteriosus (DA) diameter, and shunt direction. The measurements were performed in subcostal biatrial view for ASD and IAS, apical four chamber view for LA, RA, mitral and tricuspid annulus, and suprasternal view for DA. Further, the ratio between ASD/IAS, the ratio between LA/RA, the ratio between mitral/tricuspid annulus, the ASD peak gradient/ASD diameter and ASD diameter/(LA:RA ratio) were calculated.

The study procedures were performed in accordance with the declaration of Helsinki and the study was approved by the local Ethics Committee of the hospital.

\section{STATISTICAL ANALYSIS}

Statistical analysis was performed using SPSS version 20 (IBM SPSS Statistics for Windows, Version 20.0. Armonk, NY: IBM Corp.). Data were labelled as nominal or quantitative variables. Nominal variables were expressed as numbers or percentages. Differences between the mean between two groups were analyzed using the t-test or Fisher's exact test when appropriate. Multivariate analysis was carried out using logistic regressions. We used the need for BAS as dependent variable. The covariates were the mean interatrial pressure gradient, ASD diameter/(LA:RA ratio) and ASD peak gradient/ASD diameter. Receiver-operating characteristic curves were constructed, and areas under curve were calculated. Sensitivities and specificities were determined for the ability to identify cases that need septostomy. A p-value of $<0.05$ was considered statistically significant, and all $\mathrm{p}$ values were two-tailed. 
TABLE 1. Demographic data of TGA patients

\begin{tabular}{lccc}
\hline & $\begin{array}{c}\text { BAS } \\
(\mathbf{n = 2 1 )}\end{array}$ & $\begin{array}{c}\text { No BAS } \\
(\mathbf{n = 1 6 )}\end{array}$ & $\mathbf{p}$ \\
\hline $\mathrm{GA}$ & $38.38 \pm 0.93$ & $38.31 \pm 0.70$ & 0.8 \\
$\mathrm{Gender,} \mathrm{male} \mathrm{(n/ \% )}$ & $16(76.19 \%)$ & $13(81.25 \%)$ & 1.0 \\
Weight $(\mathrm{kg})$ & $3.21 \pm 0.90$ & $3.33 \pm 0.27$ & 0.6 \\
Intrauterine diagnosis (y-n/\%) & $8(30.09 \%)$ & $5(31.25 \%)$ & 0.7 \\
Small VSD (y - n/\%) & $5(23.80 \%)$ & $1(6.25 \%)$ & 0.2 \\
$\mathrm{SaO}_{2}$ & $65.71 \pm 9.97$ & $81.81 \pm 2.92$ & 0.0001 \\
Age at 1st Echo exam (hours) & $26.45 \pm 31.22$ & $78.75 \pm 104.73$ & 0.03 \\
Age at BMS (hours) & $33.76 \pm 31.13$ & - & \\
\hline
\end{tabular}

BAS - balloon atrial septostomy; GA - gestational age; $\mathrm{SaO}_{2}$ - oxygen saturation; TGA - transposition of the great arteries

\section{RESULTS}

\section{DEMOGRAPHIC DATA}

Thirty-seven consecutive neonates with simple TGA or TGA associated with a small, hemodynamically nonsignificant VSD were studied. The patients were divided into two groups according to their evolution: patients who needed BAS $(\mathrm{n}=21)$ and those without need for BAS ( $\mathrm{n}$ $=16$ ). The main characteristics of the study groups are presented in Table 1. There was no significant difference regarding gestational age (GA), body weight, or the presence of a small VSD between the two groups ( $p=0.8, p=$ 0.6 , and $\mathrm{p}=0.206$, respectively). There was a predominance of male newborns in the studied population ( $\mathrm{n}=$ 29/37, 78.37\%), however without any difference between the two groups $(p=1)$. Oxygen saturation was significantly lower in the group that needed BAS, compared to the one without BAS, as a clinical marker of poor mixing between the systemic and pulmonary circulation $(65.71 \pm 9.97$ vs.

TABLE 2. Echocardiographic parameters in TGA patients with BAS compared to those without BAS

\begin{tabular}{lccc}
\hline Variable & $\begin{array}{c}\text { BAS } \\
(\mathbf{n}=\mathbf{2 1})\end{array}$ & $\begin{array}{c}\text { No BAS } \\
(\mathbf{n}=\mathbf{1 6})\end{array}$ & $\mathbf{p}$ \\
\hline ASD diameter (mm) & $3.05 \pm 0.92$ & $5.18 \pm 0.93$ & 0.0001 \\
IAS length (mm) & $18.52 \pm 4.85$ & $17.27 \pm 4.33$ & 0.4 \\
ASD diameter/IAS length & $0.21 \pm 0.22$ & $0.40 \pm 0.47$ & 0.1 \\
ASD peak gradient & $9.80 \pm 4.72$ & $6.48 \pm 3.46$ & 0.02 \\
ASD peak gradient/ASD diameter & $3.55 \pm 2.39$ & $1.33 \pm 0.83$ & 0.001 \\
ASD mean gradient & $5.14 \pm 2.37$ & $3.06 \pm 1.84$ & 0.006 \\
IAS aneurism (y - n/\%) & $5(31.25 \%)$ & $8(38.09)$ & 0.1 \\
LA transverse diameter (mm) & $16.21 \pm 1.98$ & $15.11 \pm 1.63$ & 0.08 \\
RA transverse diameter (mm) & $14.50 \pm 1.72$ & $15.00 \pm 1.84$ & 0.4 \\
LA:RA ratio & $1.12 \pm 0.12$ & $1.01 \pm 0.13$ & 0.01 \\
ASD diameter/( LA:RA) & $2.72 \pm 0.79$ & $5.19 \pm 1.27$ & 0.0001 \\
Mi valve diameter (mm) & $10.22 \pm 1.66$ & $10.68 \pm 1.16$ & 0.3 \\
Tr valve diameter (mm) & $11.82 \pm 2.10$ & $12.31 \pm 1.26$ & 0.4 \\
Mi/Tr & $0.88 \pm 0.15$ & $0.87 \pm 0.16$ & 0.9 \\
DA (mm) & $3.48 \pm 0.80$ & $4.11 \pm 1.16$ & 0.05 \\
DA shunt (bidirectional - n/\%) & $5(23.80 \%)$ & $1(6.25 \%)$ & 0.2 \\
\hline
\end{tabular}

ASD - atrial septal defect; BAS - balloon atrial septostomy; DA - ductus arteriosus; grad - gradient; IAS - interatrial septum; LA - left atrium; Mi - mitral; RA - right atrium; TGA - transposition of the great arteries; $\operatorname{Tr}$ - tricuspid valve 
TABLE 3. Multivariable logistic regression analysis for prediction of the need for BAS

\begin{tabular}{lccc}
\hline Variable & \multicolumn{3}{c}{ Multivariate } \\
\cline { 2 - 4 } & Odds ratio & $\mathbf{9 5 \%} \mathbf{~ C I}$ & $\mathbf{p}$ \\
\hline ASD mean gradient & 0.66 & $0.19-2.25$ & 0.5 \\
ASD diameter/( LA:RA) & 9.17 & $1.25-67.36$ & 0.03 \\
ASD peak gradient/ASD diameter & 1.35 & $0.14-12.54$ & 0.7 \\
\hline
\end{tabular}

ASD - atrial septal defect; BAS - balloon atrial septostomy; LA - left atrium; RA - right atrium

$81.81 \pm 2.92, \mathrm{p}=0.0001)$. Furthermore, the mean age at the time of the first echocardiographic examination was significantly lower in the group with septostomy (26.45 \pm 31.22 hours vs. $78.75 \pm 104.73$ hours, $p=0.037$ ). This could be explained by the poor clinical condition of the patients in the group with septostomy, with severe cyanosis.

\section{ECHOCARDIOGRAPHIC DATA}

The echocardiographic parameters recorded in the two groups are presented in Table 2 . We found that the ASD size was significantly lower and peak interatrial pressure gradient, mean interatrial pressure gradient, and ratio between LA/RA were significantly higher in TGA patients with BAS, compared with those without BAS.

We also calculated two new parameters: ASD peak gradient/ASD diameter and ASD diameter/(LA:RA ratio), and

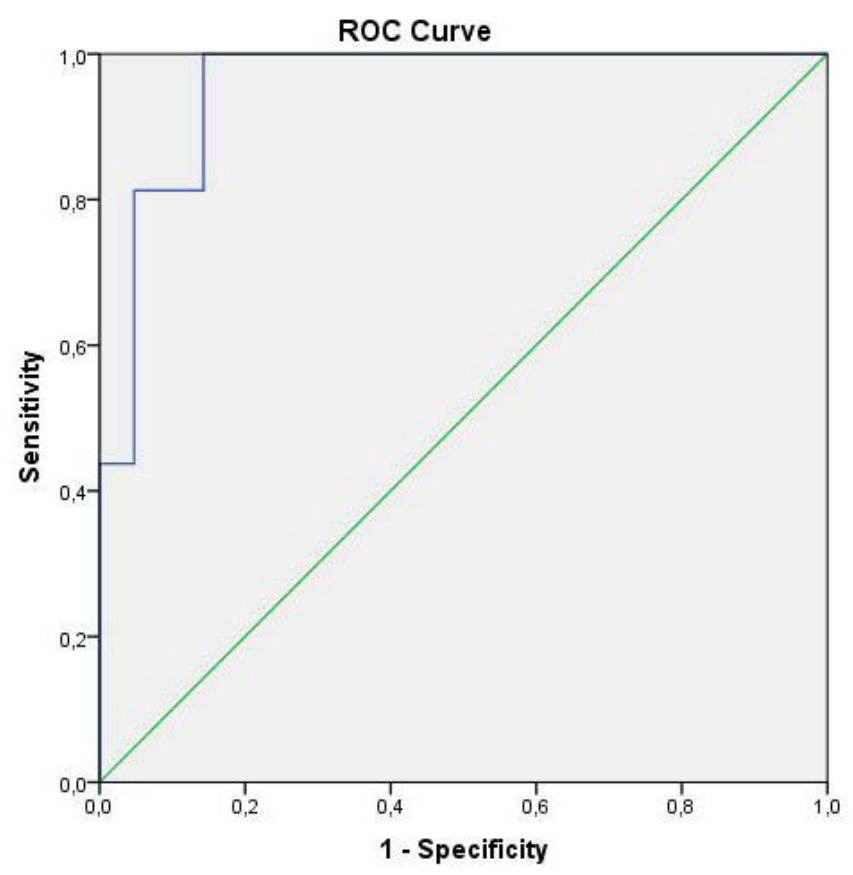

FIGURE 1. ROC analysis of ASD diameter/(LA:RA), showing an AUC of 0.95 ( $95 \% \mathrm{Cl} 89-100 \% ; p=0.0001$ ), with a sensitivity of $100 \%$ and a specificity of $33 \%$. found that ASD peak gradient/ASD diameter was significantly higher, but ASD diameter/(LA:RA ratio) was significantly lower in the group that required BAS compared with the group without BAS.

There was no difference between the groups regarding the other studied echocardiographic parameters.

\section{PREDICTIVE VALUE OF ECHOCARDIOGRAPHY}

We performed a multivariable logistic regression analysis, considering the BAS requirement as dependent variable and the mean interatrial pressure gradient, ASD diameter/ (LA:RA ratio) and ASD peak gradient/ASD diameter as covariates. After checking for these covariates, multivariate analysis showed that ASD diameter/(LA:RA ratio) was an independent predictor of the need for BAS (Table 3).

ROC analysis identified a cut-off value of 2.58 for the ASD diameter/(LA:RA ratio) as being associated with the highest predictive power for BAS requirement (Figure 1).

\section{DISCUSSION}

\section{TGA - A NEONATAL EMERGENCY}

TGA is a cyanotic CHD that represents a neonatal cardiac emergency and requires urgent initiation of proper treatment, early after birth. Currently, it is recommended that in cases diagnosed during the fetal period, the delivery should take place at or near a tertiary-care pediatric cardiac surgery center. ${ }^{11}$ The most severe forms presented in emergency settings are newborns with inadequate intercirculatory mixing. In these patients, beside the PGE1 infusion, creation of an unrestrictive interatrial communication by BAS is mandatory. ${ }^{11}$

\section{ECHOCARDIOGRAPHY IN CRITICAL CHD}

Echocardiography is the gold standard in the diagnosis of critical CHD in newborns, as well as in the postoperative follow-up of these cases. ${ }^{20-24}$ Furthermore, there are sev- 
eral studies that emphasize the role of echocardiography in decision-making in different critical CHDs in newborns. Some new compound echocardiographic parameters have been described in other pediatric cardiology pathology. For instance, the carotid-subclavian index, ${ }^{22,25,26}$ the isthmus/ductus ratio ${ }^{27}$ or a combination between ventricular disproportion, aortic and ductal isthmus measurements can help to better characterize aortic coarctation in newborns and fetuses. ${ }^{28,29}$ In pulmonary atresia with intact ventricular septum, a critical CHD with ductal-dependent pulmonary circulation, the tricuspid valve $\mathrm{z}$ score, and the right to left ventricular ratios were described as predictors of outcome in fetuses and neonates as well. ${ }^{21,30-32}$

\section{ECHOCARDIOGRAPHY IN BAS PERFORMANCE DECISION-MAKING}

The echocardiographic assessment of the interatrial communication in critical CHDs is extremely important. A restrictive ASD can be fatal in these defects, and a BAS can be life-saving. For now, there is no consensus in the literature regarding the definition of restrictive ASD. According to some authors, a restrictive ASD is defined arbitrary as a mean gradient of $8 \mathrm{mmHg}$. On the other hand, a mean gradient of less than $3 \mathrm{mmHg}$ defines a non-restrictive ASD. Values between 3-8 mmHg are considered inconclusive, being influenced by the degree of the pulmonary blood flow. ${ }^{33}$ Regarding the ASD size, some authors consider that a color jet of $3 \mathrm{~mm}$ or less across the interatrial septum can define a severely restrictive interatrial communication. ${ }^{34}$ According to others, an ASD is restrictive when there is a pressure gradient between the left and the right atria, and the size indexed to the body surface area is less than $6 \mathrm{~mm} .{ }^{35}$ Kuhn et al. considered that a foramen ovale is restrictive if the greatest diameter is $<4 \mathrm{~mm}$ and the peak velocity is $>2 \mathrm{~m} / \mathrm{s} .^{36}$

Although the decision on performing BAS in TGA patients relies mainly on clinical outcomes, echocardiography is able to add valuable information. In our study, we found that some echocardiographic parameters can predict the need for BAS in newborns with TGA. Besides the known parameters, such as ASD size, peak interatrial pressure gradient, or mean interatrial pressure gradient, in the present study we have described three other composed parameters: the LA/RA ratio, ASD diameter/(LA:RA ratio), and ASD peak gradient/ASD diameter, which were significantly modified in the TGA group with BAS compared to that without BAS. As the pulmonary effective blood flow in TGA is dependent on the size of DA, and in our study there was no significant difference regarding the DA size between the two groups, we considered that the pulmonary blood flow was comparable in our patients.

Furthermore, our results show that ASD diameter/ (LA:RA ratio) with a cut-off value of 2.58 is the best predictor of inadequate mixing and BAS requirement in simple TGA patients. To thte best of our knowledge, this is the first study that describes the above mentioned echocardiographic parameters in TGA children.

\section{STUDY LIMITS}

Firstly, this is a retrospective study, and measurements were made offline on echocardiographic recordings. Secondly, the study group was relatively small, thus the results of our study have to be validated in future studies.

\section{CONCLUSION}

ASD diameter/(LA/RA ratio) is an echocardiographic parameter that can provide supplementary information regarding adequate mixing and BAS requirement in neonates with TGA.

\section{CONFLICT OF INTEREST}

Nothing to declare.

\section{ACKNOWLEDGEMENT}

Iolanda Muntean and Daniela Toma contributed equally to this work.

This research was partially supported via the research contract number 41-042/2007, entitled "Translation of genomic research related to etiology of Congenital Heart Diseases into innovative methods for screening, prenatal prevention and 3D imaging-MAMI" financed by the Romanian Ministry of Education and Research.

\section{REFERENCES}

1. Samanek M. Congenital heart malformations: prevalence, severity, survival, and quality of life. Cardiol Young. 2000;10:179-185.

2. Blue GM, Kirk EP, Giannoulatou E, et al. Targeted nextgeneration sequencing identifies pathogenic variants in familial congenital heart disease. J Am Coll Cardiol. 2014;64:2498-506. doi: 10.1016/j.jacc.2014.09.048.

3. Fahed AC, Gelb BD, Seidman JG, Seidman CE. Genetics of Congenital Heart Disease. The glass half empty. Circ Res. 2013;112:707-720. doi: 10.1161/CIRCRESAHA.112.300853.

4. Kuehl K, Loffredo C, lammer EJ, Iovannisci DM, Shaw GM. 
Association of Congenital Cardiovascular Malformations With 33 Single Nucleotide Polymorphisms of Selected Cardiovascular Disease-Related Genes. Birth Defects Res A Clin Mol Teratol. 2010;88:101-110. doi: 10.1002/bdra.20630.

5. Pierpoint ME, Basson CT, Benson DW Jr, et al. Genetic Basis for Congenital Heart Defects: Current Knowledge. A scientific Statement From the American Heart Association Congenital Cardiac Defects Committee, Council on Cardiovascular Disease in the Young: Endorsed by the American Academy of Pediatrics. Circulation. 2007;115:3015-3038. doi: 10.1161/ CIRCULATIONAHA.106.183056.

6. Togănel R, Muntean I, Duicu C, Făgărăşan A, Gozar L, Bănescu C. The role of eNOS and AGT gene polymorphisms in secondary pulmonary arterial hypertension in Romanian children with congenital heart disease. Rev Romana Med Lab. 2013;21:267274. doi: 10.2478/rrlm-2013-0031.

7. Muntean I, Togănel R, Benedek T. Genetics of Congenital Heart Disease: Past and Present. Biochem Genet. 2017;55:105123. doi: $10.1007 / \mathrm{s} 10528-016-9780-7$.

8. Unolt M, Putotto C, Silvestri LM, et al. Transposition of great arteries: new insights into the pathogenesis. Front Pediatr. 2013;1:11. doi: 10.3389/fped.2013.00011.

9. De Luca A, Sarkozy A, Consoli F, et al. Familial transposition of the great arteries caused by multiple mutations in laterality genes. Heart. 2010;96:673-677. doi: 10.1136/hrt.2009.181685.

10. Villafane J, Lantin-Hermoso MR, Bhatt $A B$, et al. D-Transposition of the great arteries: Hot topics in the current era of the arterial switch operation. J Am Coll Cardiol. 2014;64:498-511. doi: 10.1016/j.jacc.2014.06.1150.

11. Sarris GE, Balmer C, Bonou P, et al. Clinical guidelines for the management of patients with transposition of the great arteries with intact ventricular septum. Cardiol Young. 2017;27:530-569. doi:10.1017/S1047951117000014.

12. Al-Ata JA. Balloon atrial septostomy in patient with dextrotransposition of the great arteries with insufficient mixing: 18 years of experience. JKAU: Med. Sci. 2010;17:73-89. doi: 10.4197/Med.17-4.6.

13. Feltes TF, Bacha E, Beekman RH, et al. Indications for Cardiac Catheterization and Intervention in Pediatric Cardiac Disease A Scientific Statement From the American Heart Association. Circulation. 2011;123:2607-2652. doi: 10.1161/ CIR.ob013e31821b1f10.

14. Mukherjee D, Lindsay M, Zhang Y, et al. Analysis of 8681 neonates with transposition of the great arteries: outcomes with and without Rashkind balloon atrial septostomy. Cardiol Young. 2010;20:373-380. doi: 10.1017/S1047951110000296.

15. Peterson C, Ailes E, Riehle-Colarusso T, et al. Late detection of critical congenital heart disease among US infants. Estimation of the potential impact of proposed universal screening using pulse oxymetry. JAMA Pedaitrics. 2014;168:361-370. doi: 10.1001/jamapediatrics.2013.4779.

16. Jawin V, Ang H-L, Omar A, Thong M-K. Beyond Critical Congenital Heart Disease: Newborn Screening Using Pulse Oximetry for Neonatal Sepsis and Respiratory Diseases in a Middle-Income Country. PLoS ONE 2015;10:e0137580. doi: 10.1371/journal.pone.0137580.

17. Knowlles R, Griebsch I, Dezateux C, Brown J, Bull C, Wren C. Newborn screening for congenital heart defects: a systematic review and cost-effectiveness analysis. Health Technol Assess. 2005;9:1-152.

18. Eckersley L, Sadler L, Parry E, Finucane K, Gentles TL.
Timing of diagnosis affects mortality in critical congenital heart disease. Arch Dis Child. 2016;101:516-520. doi: 10.1136/ archdischild-2014-307691.

19. Mahle WT, Gonzalez JH, Kreeger J, Marx G, Duldani G, Silverman NH. Echocardiography of transposition of the great arteries. Cardiol Young. 2012;22:664-670. doi: 10.1017/ S1047951112001503.

20. Lopez L, Colan SD, Frommelt PC, et al. Recommendations for quantification methods during the performance of a pediatric echocardiogram: a report from the pediatric measurements writing group of the American Society of Echocardiography Pediatric and Congenital Heart Disease Council. J Am Soc Echocardiogr. 2010;23:465-495. doi: 10.1016/j.echo.2010.03.019.

21. Alwi M. Management algorithm in pulmonary atresia with intact ventricular septum. Catheter Cardiovasc Interv. 2006;67:679-686. doi: 10.1002/ccd.20672.

22. Dodge-Khatami A, Ott S, Di Bernardo S, Berger F. Carotidsubclavian artery index: new echocardiographic index to detect coarctation in neonates and infants. Ann Thorac Surg. 2005;80:1652-1621. doi: 10.1016/j.athoracsur.2005.04.041.

23. Amoozgar H, Salaminia S, Amirghofran AA, et al. Evaluation of cardiac and valvular function after arterial switch operation: a midterm follow-up. Int Cardiovasc Res J. 2013;7:83-89.

24. Suteu CC, Muntean I, Benedek T, Togănel R. Giant dissecting ventricular septal haematoma associated with critical congenital heart disease. Interact Cardiovasc Thorac Surg. 2016;23:837-838. doi: 10.1093/icvts/ivw223.

25. Peng DM, Punn R, Maeda K, Selamet Tierney ES. Diagnosing Neonatal Aortic coarctation in the setting of Patent Ductus Arteriosus. Ann Thorac Surg. 2016;101:1005-1010. doi: 10.1016/j.athoracsur.2015.09.050.

26. Mivelaz Y, Di Bernardo S, Meijboom EJ, Sekarski N. Validation of two echocardiographic indexes to improve the diagnosis of complex coarctations. Eur J Cardiothorac Surg. 2008;34:10511056. doi: 10.1016/j.ejcts.2008.07.036.

27. Lu CW, Wang JK, Chang CI, et al. Noninvasive diagnosis of aortic coarctation in neonates with patent ductus arteriosus. J Pediatr. 2006;148:217-221. doi: 10.1016/j.jpeds.2005.09.036.

28. Familiari A, Morlando M, Khalil AA, Sven-Erik S, et al. Risk factor for coarctation of the aorta on prenatal ultrasound: a systemic review and meta-analysis. Circulation. 2017;136:24. doi: 10.1161/CIRCULATIONAHA.116.024068.

29. Mărginean C, Mărginean CO, Muntean I, Togănel R, Voidăzan S, Gozar L. The role of ventricular disproportion, aortic and ductal isthmus ultrasound measurements for the diagnosis of fetal aortic coarctation, in the third trimester of pregnancy. Med Ultrason. 2015;17:475-481. doi: 10.11152/ mu.2013.2066.174.rvd.

30. Daubeney PE, Sharland GK, Cook AC, Keeton BR, Anderson $\mathrm{RH}$, Webber SA. Pulmonary atresia with intact ventricular septum: impact of fetal echocardiography on incidence at birth and postnatal outcome. UK and Eire Collaborative Study of Pulmonary Atresia with Intact Ventricular Septum. Circulation. 1998;98:562-566.

31. Peterson RE, Levi DS, Williams RJ, Lai WW, Sklansky MS, Drant S. Echocardiographic predictors of outcome in fetuses with pulmonary atresia with intact ventricular septum. J Am Soc Echocardiogr. 2006;19:1393-1400. doi: 10.1016/j. echo.2006.05.021l.

32. Salvin JW, McElhinney DB, Colan SD, et al. Fetal tricuspid 
valve size and growth as predictors of outcome in pulmonary atresia with intact ventricular septum. Pediatrics. 2006;118:e415-e420. doi: 10.1542/peds.2006-0428.

33. Graziano JN, Heidelberger KP, Ensing GJ, Gomez CA, Ludomirsky A. The influence of a restrictive atrial septal defect on pulmonary vascular morphology in patients with hypoplastic left heart syndrome. Pediatr Cardiol. 2002;23:146151.

34. Canter CE, Moorehead S, Huddleston CB, Spray TL. Restrictive atrial septal communication as a determinant of outcome of cardiac transplantation for hypoplastic left heart syndrome. Circulation. 1993;88:II456-II460.

35. Dash PK, Satpathy M. Atrial septal defect (secundum type). In: Sathpathy M, Mishra BR. Clinical Diagnosis of Congenital heart disease. Jaypee/The Health Sciences Publisher/New Delhi, 2015; p. 76-84.

36. Kuhn MA, Larsen RL, Mulla NF, Jofnston JK, Chinnock RE, Bailey LL. Outcome of infants with hypoplastic left heart syndrome who undergo atrial septostomy before heart transplantation. Am J Cardiol. 2000;85:124-127. 